\title{
Wheat harvesting by combine with GPS receiver and grain sensor
}

\author{
Komil Astanakulov ${ }^{1 *}$, Kodir Shovazov ${ }^{1}$, Atkham Borotov $^{1}$, Akram $^{\text {Turdibekov }}{ }^{1}$ and \\ Saidmukhammad Ibrokhimov ${ }^{2}$ \\ ${ }^{1}$ TIIAME, Agricultural Machines Department, 100000, 39 Kari Niyaziy str., Tashkent, Uzbekistan \\ ${ }^{2}$ SRDI "UZDAVYERLOYIHA", 100097, 5 Chapanata str., Tashkent, Uzbekistan
}

\begin{abstract}
This research describes the result of study and analyze the working process of the harvester combine with GPS receiver and grain level sensor in wheat harvesting. GPS receiver and grain level sensor showed that the combine harvester was working with what level of velocity in the real time regime and how much grain was being uploaded into grain tank. According to results when the yield increased from 2.62 $\mathrm{t} / \mathrm{ha}$ to $6.22 \mathrm{t} / \mathrm{ha}$, because of decreasing the work-velocity of the combine harvester, the work efficiency of the combine harvester decreased from $1.96 \mathrm{ha} /$ hour till $1.30 \mathrm{ha} /$ hour, and grain loss rose from 2.03 per cent till 3.76 per cent. In the field where the weeds had covered 16.8 per cent, the work efficiency of the combine was $1.74 \mathrm{ha} /$ hour, in another field where weeds level was 56.7 the work efficiency of the combine decreased almost 1.7 times, made up $1.07 \mathrm{ha} /$ hour, the grain loss was observed that it increased from 2.1 per cent till 7.42 per cent. When the moisture of the cereal decreased it was defined that the combine work efficiency increased, however the rate of grain loss in the header rose too. Keywords: GIS, harvester combine, GPS receiver, grain level sensor, wheat harvesting, work efficiency.
\end{abstract}

\section{Introduction}

In farms the combine harvesters are being used in different conditions, namely they are being used with the same working regime in low or high yield, grassy or lain down fields as well in condition that the moisture of the cereal is lower than measures. As a result, in some areas the grain loss level is reaching till 15-20 per cent, fuel expense is consisting of 35-40 $\mathrm{kg}$ for one hectare, and even in some situations $45-50 \mathrm{~kg}$, therefore the effectiveness of the combine harvester is being low.

One of the more perspective ways of increasing effect managing agricultural production is using informative system on the base of geo-information technology. The similar systems allow solving planned agro technical operation, monitoring agro technical operations and condition of crops, forecasting the yield of the crop and evaluation losses, planning, monitoring and analyzing the used technics. Such data must be completed by an accurate

\footnotetext{
*Corresponding author: komil_uzmei@mail.ru
} 
position on the Earth, specifically using all modern methods: GIS based digital maps, GPS, GNSS satellite systems, etc. [1].

GIS technologies are used for defining the using efficiency of the combine harvesters. Steering system for combine harvester based on machine vision was developed for increasing the efficiency of harvesting works by using GIS technologies [2, 22].

It is important to intrude GPS receivers and yield sensors for using GIS technologies in agricultural machines. Some works have been performed for intruding GPS receivers and sensors as well using correctly them.

In India, an automated yield monitoring system consisting of a yield sensor, global positioning system (GPS), field computer with custom software was mounted on a selfpropelled indigenous grain combine harvester for real-time crop yield mapping along with moisture data. By means of optical sensors (light emitter and detector), the height of the grain on the elevator paddles was measured and converted in the grain mass flow. Three rice fields were harvested to evaluate the performance of the yield monitor for grain yield and moisture mapping of harvested grains. The actual yield maps were generated by using ArcGIS software from the data collected for three different rice fields. The total area harvested by using indigenous combine harvester fitted with yield monitor and moisture sensor was 0.84 ha comprising three fields having areas $0.3,0.22$ and 0.32 ha respectively. On an average, yields for all the three fields were $4325.91,5093.14$ and $4287.66 \mathrm{~kg} \mathrm{ha}^{-1}$ with moisture content of $21.42 \%, 22.78 \%$ and $20.42 \%$ (wet basis) recorded respectively [3, 4].

In harvesting of the wheat in autonomous navigation of tracked combine harvester, the state and posture can be obtained from the positioning and inertial sensor measurements. But these sensor measurements have measurement uncertainties, which can be compensated by using the tracked combine harvester kinematic and dynamic model.

On the other hand, the computation of soil parameter and track coefficients are also important for the tracked combine harvester dynamic model. An autonomous tracked combine harvester is developed in the vehicle robotics laboratory, Hokkaido University based on Real Time Kinematic Global Positioning System (RTK-GPS) and Inertial Measurement Unit (IMU) for the harvesting of wheat and paddy [5].

Some researchers focused on degree of lodging at harvest time an alternative of yield. It depends on completion of extension of spikes up to heading stage and too much $\mathrm{N}$ and lack of sunshine make lodging large. A relationship between lodging and these are few after the heading stage. Also, excessive $\mathrm{N}$ application in paddies leads to lodging and decreased grain quality. They estimated that rough estimates of yield were possible by looking at the degree of lodging [6,7].

Researchers observed to estimate the absolute heading of robot combine harvesters by compensating this gyro measurement bias during non-linear turning maneuvers. Therefore, this estimation method can be used to estimate the absolute heading when the tracked combine harvester will makes turn at high speed and with high order steering commands in order to cut wheat and paddy rice near headlands to calculate the exact crop periphery for the development of a harvesting map [8].

In general, a single sensor is not able to provide enough information, whereas multisensor integration can provide more useful information, which is more helpful and informative than what can be observed using a single sensor. This information needs to be fused in a way that reduces sensor uncertainties and the additional task of interpretation must be performed [9]. However, it can be cause combine to become complicated and expensive. Therefore, it is necessary to take important results by using less sensors than usually.

In general, main aim of using new techologies during the harvesting process is to make longer the work time of the combine harvester. Niehaus used spatial data to evaluate the 
corn harvesting operation on an Iowa grain farm and reported an overall TE of $62.4 \%$; with $16.1 \%$ of total time spent in machine idling, $9.1 \%$ in in-field or road travel, $9.3 \%$ in turning within field headlands, and $2.9 \%$ unloading grain while not harvesting [10].

Other scientists compared the practical collection methods of cereal harvesting costs in different agricultural holdings in order to effectively manage combine harvester fleets, make economically reasoned decisions on the exploitation of combine harvesters, reduce harvesting costs and consequently the cost price of cereals. Analyzed this information and provided assessments on the effectiveness of their combine harvester fleet [11].

\section{Materials and methods}

\subsection{Study area}

This study was conducted on 18-hectare irrigated, almost float cropland area of Yangiyul district of Tashkent region (Uzbekistan). The district lies in the middle of the Tashkent oasis and covers $431.5 \mathrm{~km} 2$ area of region The corresponding time zone is $\mathrm{UTC}+5$ (UZT) (Fig. 1). On the main part of the district, the vegetation period of plants exceeds 180-200 days. Favorable climatic terms allow tilling a cotton plant, winter wheat and other heat-loving cultures, get 2-3 harvests of vegetables in a year. Generally, taking into account weather condition, winter wheat is sowed between middle of autumn and beginning of winter.

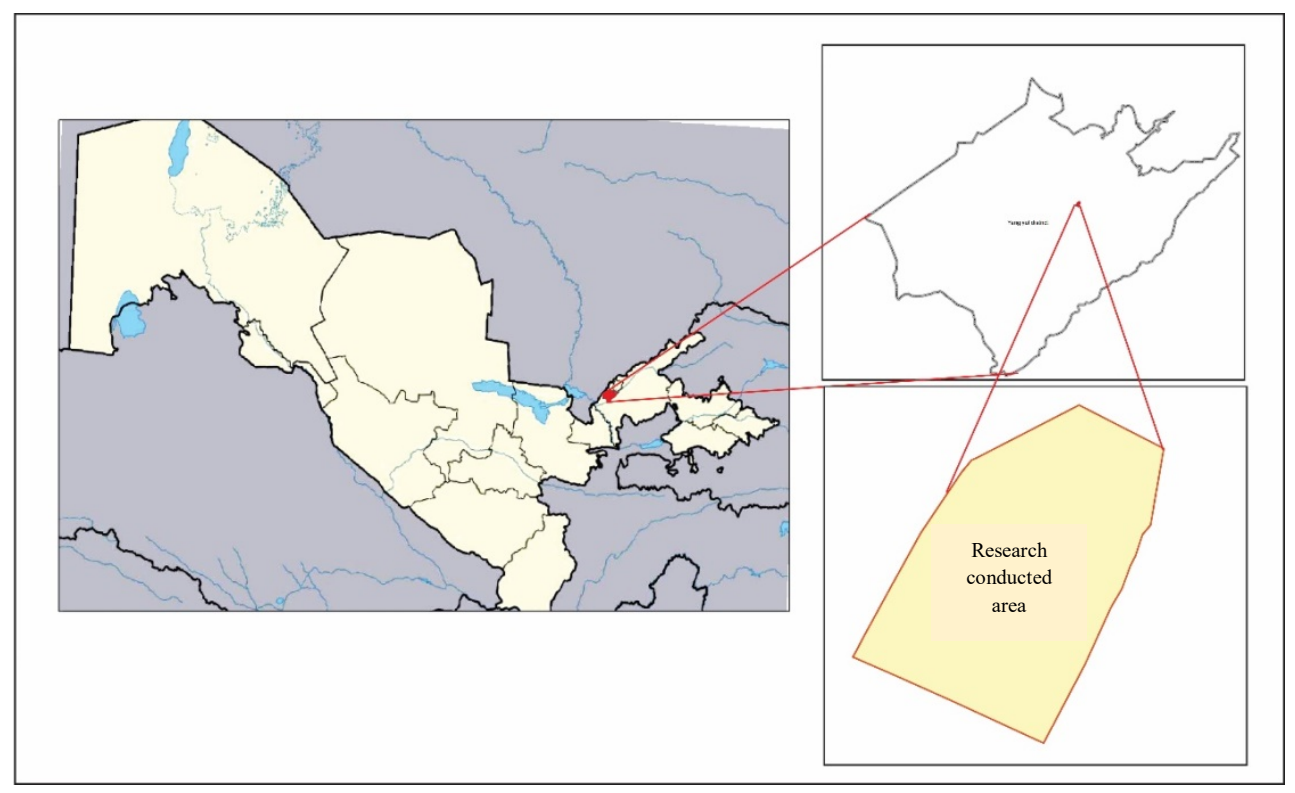

Fig. 1. Study area

\subsection{Methodology}

For carrying experiments, the experimental harvester combine was prepared at a base of combine Dominator-130 (Fig. 2) according to previous researchers' results in this direction [12-15]. 


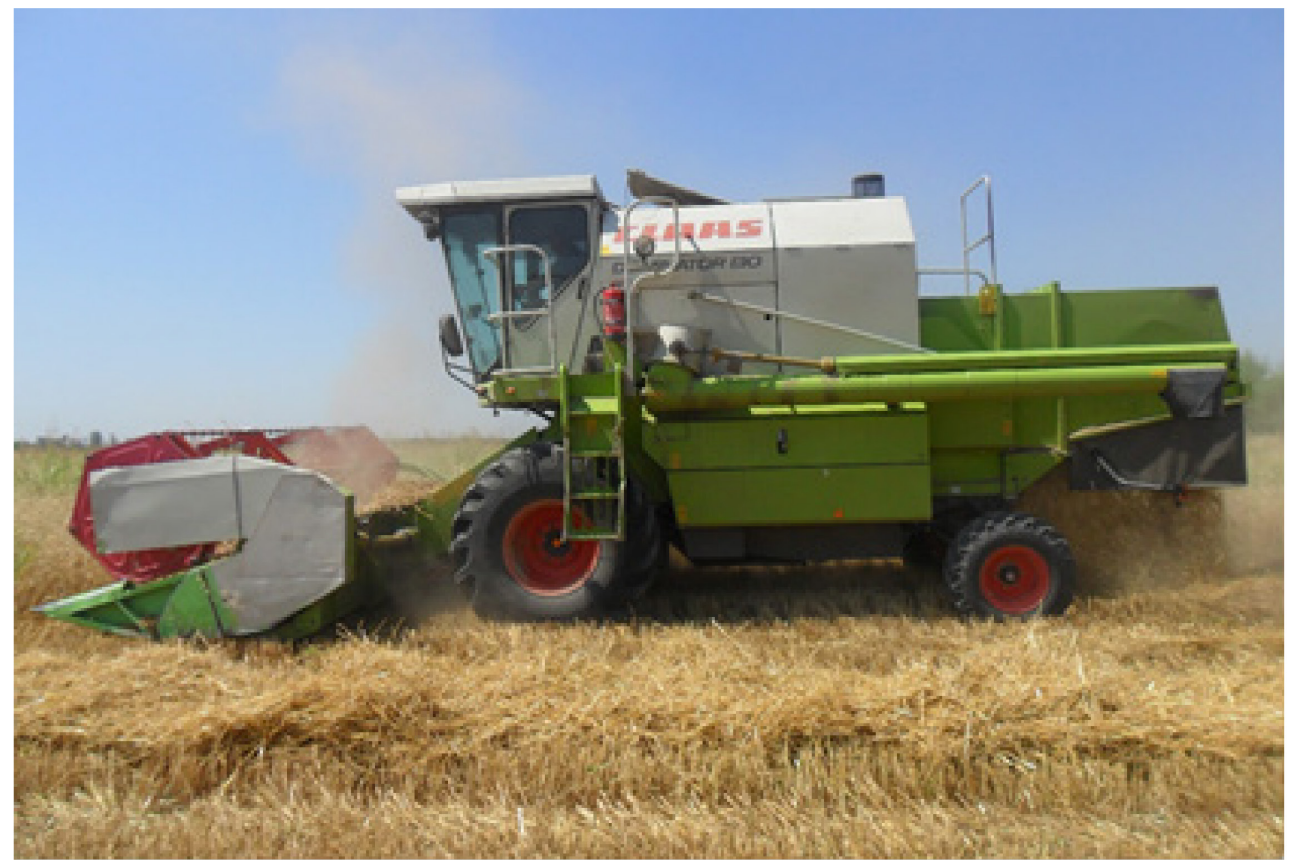

Fig. 2. Experimental cereal combine

Above mentioned Han and others developed method to evaluate auto guidance systems of linear parallel-tracking applications of agricultural machines that equipped with GNSS devices [11]. Keskin used an automatic agricultural vehicle based on low cost GPS receiver for increasing the rate of them [12]. Coen developed a robot combine harvester as the aim more realizing GIS technologies during the harvesting works [13].

A cereal harvester combine was tested that equipped with GPS receiver and grain level indicator for harvesting the wheat as well the experiments for analyzing its work were performed by wheat's Krasnodar-99 sort. Size-mass and yield indicators of the cereal in the field were defined before experiments.

For taking data about work efficiencies of cereal combine Dominator-130 at real time regime the Teltonika FMB920 GNSS/GSM/Bluetooth terminal and Escort DB-2 sensor were installed in the grain tank (Fig. 3).

Teltonika FMB920 GNSS/GSM/Bluetooth terminal collects data about position and working of moving object and it sends the data to server through GSM net-work.

Teltonika FMB920 terminal gives observing opportunity the position of combine during the work in real time regime. The technical characteristics of this device as following: Bluetooth B 3.0 micro CD card (till 32 GB) internal GPS antenna, the internal GPS antenna1, number enter 1 , analog enter 1 exit were installed. Battery 170 was provided with $\mathrm{mA} /$ hour IP54.

Escort DB-2 grain sensor is installed on the wall of grain tank, it defines the fluctuation of every cereal and other sorts of productions that their moisture does not increase from 25 per cent and sends the data to observing system through artificial satellite. The high level of the defense (IP 67) wide temperature gap (from - 60 till +85) guarantees reliable forking of censor indicator in every climate condition and in different relief. The sensor is suitable for different types of GLONASS/GPS terminals. 


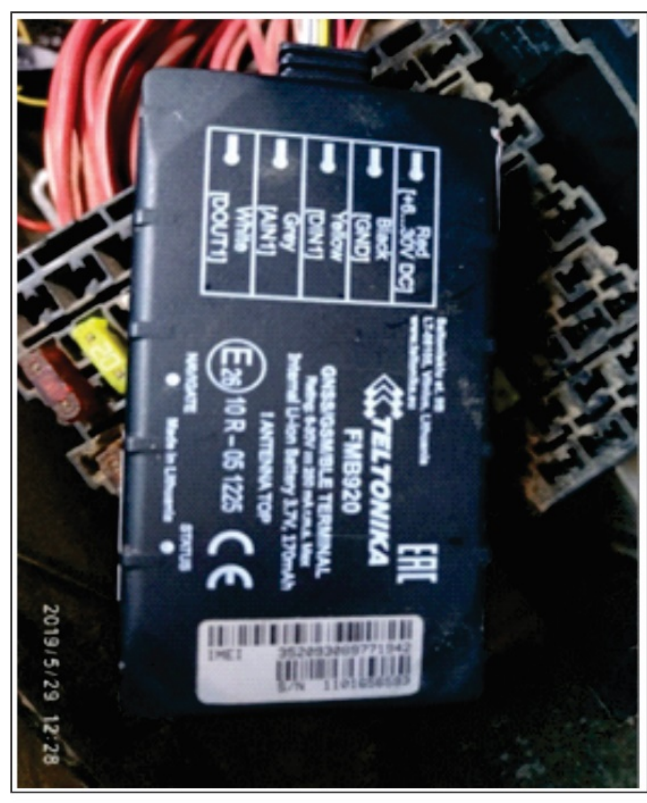

a

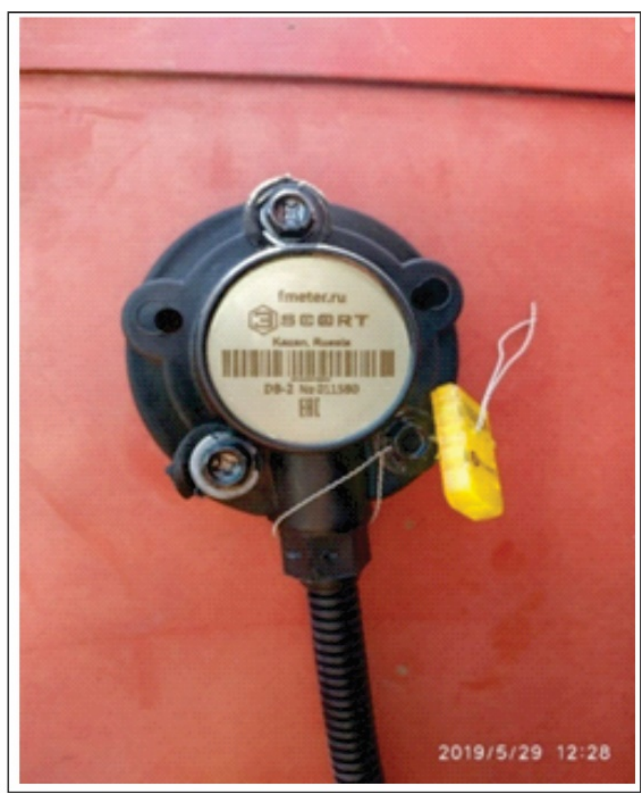

b

Fig. 3. Teltonika FMB920 GNSS/GSM/Bluetooth terminal (a) and Escort DB-2 sensor (b)

During the experimental-test the work regimes and technological parameters of the combine Dominator-130 are as following: installing height of header $-20 \mathrm{~cm}$; rotation frequency of drum - $1200 \mathrm{rpm}$; clearance between concave and drum: entering part - 13 $\mathrm{mm}$; exiting part - $3 \mathrm{~mm}$; opening angle of sieve jalousies - 30 degree; rotation frequency of fan $-800 \mathrm{rpm}$. When the influence of installing height of header to work efficiency indicators was studied, the cutting height was changed from $10 \mathrm{~cm}$ till $50 \mathrm{~cm}$ with $10 \mathrm{~cm}$ step. Also, working speed of the combine harvester was in diapason 4-6 km/hour according to fed cereal mass into thresher and working condition.

In defining work and idle movement of combine in field Oksanen's results were used about coverage path planning algorithms for agricultural field in moving zone of agricultural machines [16].

\section{Results and discussion}

According to obtained data through GPS receiver, work efficiency of combine decreases while grain yield increases in work process of combine. Grain loss consisted of 1.96 ha/hour when yield became $2.62 \mathrm{t} / \mathrm{ha}$, the rate of grain loss decreased to $1.78 \mathrm{ha} /$ hour when yield became $3.58 \mathrm{t} / \mathrm{ha}$, then with yield increased the grain loss rose too (Table 1).

The grain loss in combine header almost did not change, when yield rose from $4.46 \mathrm{t} / \mathrm{ha}$ to $6.24 \mathrm{t} / \mathrm{ha}$, losses behind the combine increased from 2.72 per cent till 3.76 per cent, and work efficiency declined from 1.63 ha/hour till 1.30 ha/hour (Table 1).

According to data that was received from GPS receiver it should be mentioned that, when crop yield increased to $4.46 \mathrm{t} /$ ha and more, after that the travel speed of the combine decreased from $6 \mathrm{~km} /$ hour to $4 \mathrm{~km} /$ hour respectively.

As well in Grisso's researches: crop yield affects the field efficiency of a combine when standard or typical field speeds are used to calculate theoretical field capacities, with greater yields usually resulting in reduced travel speed due to the heavier weight of grain 
[17]. Agricultural machines field efficiencies have a significant effect on the effective field capacities of machinery, which in turn impact the overall cost of production [18].

Table 1. Influence of grain yield to work efficiency of combine Dominator-130

\begin{tabular}{|l|c|c|c|c|c|}
\hline \multirow{2}{*}{ Work quality indicators } & \multicolumn{5}{|c|}{ Grain yield (t/ha) } \\
\cline { 2 - 6 } & 2.62 & 3.58 & 4.46 & 5.63 & 6.24 \\
\hline $\begin{array}{l}\text { Work efficiency in main period } \\
\text { (ha/hour) }\end{array}$ & 1.96 & 1.78 & 1.63 & 1.50 & 1.30 \\
\hline Total grain loss (\%): & 2.19 & 2.03 & 2.72 & 3.28 & 3.76 \\
\hline - in combine header & 0.60 & 0.51 & 0.52 & 0.56 & 0.63 \\
\hline - behind the combine & 1.59 & 1.57 & 2.20 & 2.72 & 3.13 \\
\hline
\end{tabular}

When combine Dominator-130 was tested in fields where weeds level is different (Table 2), its work efficiency was 1.74 ha/hour in field where weeds level was 16.8 per cent, the work efficiency decreased almost 1.7 times and constituted 1.07 ha/hour in the field where weeds level was 56.7 per cent. In that conditions the grain loss of the combine was observed to increase to 3.5 times, namely in the first variant it was just 2.10 per cent, in the last condition the index consisted of 7.42 per cent.

In this case, it is important to emphasize that, when grassy level increases, in combine header the grain loss changes slightly, namely it reached from 0.52 per cent till 0.62 per cent. However, in the thresher changing of the grain loss was insignificantly, it reached from 1.58 per cent to 6.8 per cent, namely it rose to 4.3 times.

This situation is described that, when combine harvests the weeds cereal field the process of working units of the combine in threshing part becomes complicated and they cannot thresh, separate the grain.

Table 2. Influence of grassy level fields to work quality indicators of combine Dominator-130

\begin{tabular}{|l|c|c|c|c|c|}
\hline \multicolumn{2}{|c|}{ Work quality indicators } & \multicolumn{5}{|c|}{ Weeds level fields (\%) } \\
\cline { 2 - 6 } & 16.8 & 24.2 & 36.7 & 43.9 & 56.7 \\
\hline $\begin{array}{l}\text { Work efficiency in main period } \\
\text { (ha/hour) }\end{array}$ & 1.74 & 1.65 & 1.61 & 1.36 & 1.07 \\
\hline Total grain loss (\%): & 2.10 & 3.31 & 4.63 & 6.18 & 7.42 \\
\hline - in combine header & 0.52 & 0.58 & 0.6 & 0.62 & 0.62 \\
\hline - behind the combine & 1.58 & 2.73 & 4.03 & 5.56 & 6.80 \\
\hline
\end{tabular}

According to data that was received from GPS receiver, the travel speed of the combine was observed to decrease during crop harvesting in the field where there are many weeds.

According to results of performed experiments about studying the influence of the cereal moisture to combine work quality (Table 3).

Table 3. Influence of cereal moisture to work quality indicators of combine Dominator-130

\begin{tabular}{|l|c|c|c|c|c|}
\hline \multirow{2}{*}{ Work quality indicators } & \multicolumn{5}{|c|}{ Cereal moisture (\%) } \\
\cline { 2 - 6 } & 20.3 & 16.0 & 12.4 & 10.8 & 7.5 \\
\hline Work efficiency in main period (ha/hour) & 1.78 & 1.73 & 1.80 & 1.81 & 1.96 \\
\hline Total grain loss (\%): & 2.10 & 2.21 & 2.51 & 2.78 & 3.26 \\
\hline - in combine header & 0.43 & 0.57 & 0.89 & 1.27 & 1.44 \\
\hline - behind the combine & 1.67 & 1.64 & 1.62 & 1.51 & 1.82 \\
\hline
\end{tabular}

At high working regimes when the cereal moisture was 20.3 per cent the work efficiency in main period made up 1.78 ha/hour, grain loss was equal to 2.10 per cent, when the cereal moisture decreased from 16.0 per cent till 7.5 per cent the work efficiency rose 
from $1.78 \mathrm{ha} /$ hour till $1.96 \mathrm{ha} /$ hour. In the same time of increasing of the work efficiency the grain loss increased from 2.10 per cent to 3.26 per cent.

This situation is described that, when the cereal moisture decreased, work efficiency of combine increases as well cereal mass following rises, increasing of grain loss is described with spilling as a result its mechanical influence. It can be seen also the grain loss is being taken part mainly in combine header.

Above analyzed experiments showed that, combine harvester should be used at the suitable working regimes depending on the sort of crop, yield and grain moisture. As if like these recommendations were suggested by Pristavka and Aldoshin [19-21].

\section{Conclusion}

When Dominator-130 for cereal harvesting combine that equipped with GPS receiver and grain level indicator sensor was tested by using GIS technologies, becoming its header installing height $-20 \mathrm{~cm}$; rotation frequency of drum - $1200 \mathrm{rpm}$; clearance between concave and drum: entering and exiting part $-13 \mathrm{~mm}$ and $3 \mathrm{~mm}$ respectively; opening angle of sieve jalousies - 30 degree; rotation frequency of fan - $800 \mathrm{rpm}$, as cereal yield 3.5-3.6 t/ha, moisture - between 16-20 per cent the cereal can be harvested with little grain loss. When cereal yield, moisture and weeding level change for decreasing of grain loss combine should be used by changing its work regimes.

The study was funded by the Uzbekistan Applied Research Foundation, grant No KHA-3-009.

\section{References}

1. V. Voštová, T. Vondráčková, Proceedings of the 4th Int. Conference TECHSTA (2007)

2. E. R. Benson, J. F. Reid, Q. Zhang, ASAE Annual Meeting (2001)

3. M. Singh, R. Kumar, A. Sharma, B. Singh, P. Mishra, K. Sharma, Agricultural Engineering International: CIGR Journal, 15 (3) (2013)

4. M. Singh, J. Singh, A. Sharma, Journal of Agricultural Engineering, 48 (4) (2011)

5. Z. Zhang, N. Noguchi, K. Ishii, L. Yang, C. Zhang, IFAC Proceedings, 46 (2013)

6. E. Makino, T. Sugiyama, T. Ichikawa, K. Hamada, M. Kawanaka, Journal of JSAM. 69 (4), (2007)

7. E. Makino, T. Sugiyama, T. Ichikawa, K. Hamada, M. Kawanaka, Journal of JSAM. 69 (5), (2007)

8. M. Rahman, K. Ishii, Sensors, 18 (2018)

9. R. Adla, B. Yousef, N. Al-Holou, In Proceedings of the International Conference on Parallel and Distributed Processing Techniques and Applications (Las Vegas, 2013)

10. C. R. Niehaus, M.S Thesis, University of Illinois at Urbana-Champaign (2014)

11. J. Olt, K. Kuut, R. Ilves, A. Kuut. Research in Agricultural Engineering, 65 (1) (2019)

12. S. Han, Q. Zhang, H. Noh, B. Sin, Transactions of the ASAE, 47 (1) (2004)

13. M. Keskin, S. M. Say, Computer and Electronics in Agriculture, 54 (2006)

14. T. Coen, A. Vanrenterghem, W. Saeys, J. de Baerdemaeker, Computers and Electronics in Agriculture, 63 (2008)

15. M. Pexa, Research in Agricultural Engineering, 57 (2011)

16. T. Oksanen, A. Visala, Journal of field robotics, 26 (8) (2009) 
17. R. D. Grisso, P. J. Jasa, D. E. Rolofson, Applied Engineering in Agriculture, 18 (2) (2002)

18. S. Pitla, N. Lin, S. Shearer, J. Luck, Applied Engineering in Agriculture, 30 (6) (2015)

19. M. Pristavka, M. Bujna, M. Korenko, Journal of Central European Agriculture, 14 (2013)

20. M. Pristavka, K. Krištof, P. Findura, Agronomy Research, 15 (2017)

21. N. Aldoshin, O. Didmanidze, Research in Agricultural Engineering, 64 (2018)

22. G. Shodmonova, U. Islomov, O.Abdisamatov, Sanjar Khikmatullaev, U.Kholiyorov and Sh. Khamraeva, IOP Conf. Series: Materials Science and Engineering, 896 (2020) 